\title{
Small Scale Hydrocarbon Fire Test Concept
}

\author{
Joachim Søreng Bjørge ${ }^{1,2, *}$, Maria-Monika Metallinou ${ }^{3}$, Arjen Kraaijeveld ${ }^{3}$ and Torgrim Log ${ }^{3,4}$ \\ 1 Q Rådgivning AS/PDS Protek, Øvregata 126, 5527 Haugesund, Norway \\ 2 Department of Physics and Technology, University of Bergen, 5020 Bergen, Norway \\ 3 Western Norway University of Applied Sciences, 5528 Haugesund, Norway; \\ monika.metallinou@hvl.no (M.M.M.); Arjen.Kraaijeveld@hvl.no (A.K.) \\ 4 Statoil Kårstø, Kårstø, 5562 Tysværvåg, Norway; tlog@statoil.com \\ * Correspondence: jsb@q-rad.no; Tel.: +47-9098-1051
}

Received: 13 October 2017; Accepted: 10 November 2017; Published: 14 November 2017

\begin{abstract}
In the oil and gas industry, hydrocarbon process equipment was previously often thermally insulated by applying insulation directly to the metal surface. Fire protective insulation was applied outside the thermal insulation. In some cases, severe corrosion attacks were observed due to ingress of humidity and condensation at cold surfaces. Introducing a $25 \mathrm{~mm}$ air gap to prevent wet thermal insulation and metal wall contact is expected to solve the corrosion issues. This improved insulation methodology does, however, require more space that may not be available when refurbishing older process plants. Relocating structural elements would introduce much hot work, which should be minimized in live plants. It is also costly. The aim of the present study is therefore to develop a test concept for testing fire resistance of equipment protected with only air-gap and thermal insulation, i.e., without the fire-protective insulation. The present work demonstrates a conceptual methodology for small scale fire testing of mockups resembling a section of a distillation column. The mockups were exposed to a small-scale propane flame in a test configuration where the flow rate and the flame zone were optimized to give heat flux levels in the range $250-350 \mathrm{~kW} / \mathrm{m}^{2}$. Results are presented for a mockup resembling a $16 \mathrm{~mm}$ thick distillation column steel wall. It is demonstrated that the modern distance insulation in combination with the heat capacity of the column wall indicates $30+$ minutes fire resistance. The results show that this methodology has great potentials for low cost fire testing of other configurations, and it may serve as a set-up for product development.
\end{abstract}

Keywords: small scale fire testing; hydrocarbon fires; low cost

\section{Introduction}

The hydrocarbon process industry is still important for the modern world economy. It involves physical processes like separation, distillation, cracking, etc., to produce the products that are needed in the market. Equipment, such as distillation columns, usually requires thermal insulation to prevent heat losses or heat gains depending on their temperature span and the ambient conditions. As this is an aging industry, the equipment is gradually upgraded to extend the equipment lifetime.

During the last 3-4 decades, this industry has experienced severe accidents [1,2]. Much effort is therefore put into limiting the fire and explosion risks that are associated with processing the highly combustible hydrocarbon products. However, every year there are still severe fires in the hydrocarbon processing industry $[1,3]$. Since much of the equipment is working at elevated pressures, a loss of containment in fire-exposed equipment may violently release huge quantities of flammable materials [2,3]. Active and passive fire protection measures are therefore very important to prevent the violent escalation of industrial fires.

Corrosion protection paint was applied to prevent external corrosion of the process equipment. Mineral based thermal insulation (typically $50 \mathrm{~mm}$ thickness) was then put in direct contact with this 
paint. In order to achieve proper passive fire protection, high temperature resistant mineral based insulation (typically 30-50 mm thickness) was provided outside the thermal insulation. Stainless-steel cladding (typically $0.7 \mathrm{~mm}$ thickness) represented the outer surface preventing ingress of rain and snow. The cladding also served as flame deflection in a fire scenario protecting the passive fire protection and the thermal insulation from direct flame exposure. During the 1990's, much research was done to evaluate the fire testing procedures of installed process equipment $[4,5]$. In general, the selected solutions were demonstrated to give sufficient resistance to hydrocarbon pool fires.

After 20+ years of service, inspection has shown that it is necessary to do maintenance and rehabilitation of process equipment, such as hydrocarbon distillation columns [5]. In some cases, where the units operate below the ambient air dew point, natural convection has supplied humidity to the thermal insulation, finally becoming soaked in water. This ruins the thermal insulation capacity since only $4 \%$ moisture by volume can reduce the thermal efficiency by $70 \%$ due to the high thermal conductivity of water $[1,6]$. The aged corrosion protection paint has in several cases not been able to prevent severe corrosion attacks. A complete rehabilitation is therefore often required.

Today, an improved insulation methodology, where an air gap (typically 1 " thick) is introduced, prevents the direct contact between the thermal insulation and the steel unit. The thermal insulation is kept at this distance by perforated metal plates (aluminum or stainless steel) that are electrically insulated from the steel wall by non-conducting spacers. The new insulation method adds at least $52 \mathrm{~mm}$ to the equipment diameter. In some situations there is, however, not sufficient room available for this added spacing. Relocating structural elements would require much hot work, which should be avoided in live plants, and, shutting down the plant for such work may not be realistic. The possibility to provide room by relocating structural elements is also very costly.

Due to the typical size of such distillation columns, e.g., $4 \mathrm{~m}$ diameter and 20-25 $\mathrm{m}$ height and the operating pressures, the columns walls are comparatively thick. The walls therefore represent much thermal capacity. It could therefore in principle be a possibility that the complete system, i.e., the wall, air gap, perforated metal plate, thermal insulation, and cladding, would result in sufficiently slow temperature increase in a fire scenario. To demonstrate this by large scale testing is, however, costly. As an alternative, small scale tests may give valuable information. It was therefore decided to look for options for testing the new thermal insulation method in high heat loads.

The present work investigates a concept for the small scale testing of mockups resembling a part of a typical hydrocarbon distillation column, thermally insulated according to the modern requirements. Mockups built according to these requirements were exposed to a small-scale propane flame where the flow rate and flame zone were optimized to limit heat losses and give high heat flux levels, e.g., in the range $250-350 \mathrm{~kW} / \mathrm{m}^{2}$. The fire dynamics principles of the small-scale testing are outlined, and it is explained how it is possible to achieve heat flux levels that are normally considered only in larger scales. The design of the setup to minimize effects of limited size is discussed. Methods to document the validity of the small-scale testing are provided. Gas temperatures were recorded by mantle thermocouples, as well as a plate thermometer for heat exposure evaluations. Temperatures were also recorded in the mockup cladding, in the thermal insulation and in the steel wall sections. Results are presented for a $16 \mathrm{~mm}$ thick wall mockup. The paper describes the theoretical considerations and the physics principles involved. Then, the experiments and the results are presented. Finally, the limitations of the method are discussed regarding the potential exposure to full scale liquid fires at the location of the specific distillation column. 


\section{Theoretical Considerations}

\subsection{Fire Dynamics}

Fire testing is usually done in standardized furnaces that are fired according to given temperature time curves. Structural building elements are tested in furnaces fired in accordance with the ISO 834 temperature time curve [7]:

$$
\mathrm{T}=20+345 \cdot \log _{10}(8 \cdot t+1)\left({ }^{\circ} \mathrm{C}\right)
$$

where $t$ ( $\mathrm{min}$ ) is the exposure time. Oil and gas fires are expected to quickly result in very high flame temperatures. The standardized hydrocarbon (HC) test curve developed by the Norwegian Petroleum Directorate is therefore different from the ISO 834 temperature time curve and given by [8]:

$$
T=20+1080 \cdot\left(1-0.325 \cdot e^{-0.167 \cdot t}-0.675 \cdot e^{-2.5 \cdot t}\right)\left({ }^{\circ} \mathrm{C}\right)
$$

It should be noted that there are also other temperature time curves for less severe fire exposure situations, e.g., façade fire exposure and more severe hydrocarbon fire exposure, such as the French HydroCarbon Modified (HCM) curve. The latter one was developed as a result of several full scale fire tests where temperatures well in excess of $1100{ }^{\circ} \mathrm{C}$ were recorded. The HCM curve is given by [9]:

$$
T=20+1280 \cdot\left(1-0.325 \cdot e^{-0.167 \cdot t}-0.675 \cdot e^{-2.5 \cdot t}\right)\left({ }^{\circ} \mathrm{C}\right)
$$

The three standard temperature time curves are shown in Figure 1.

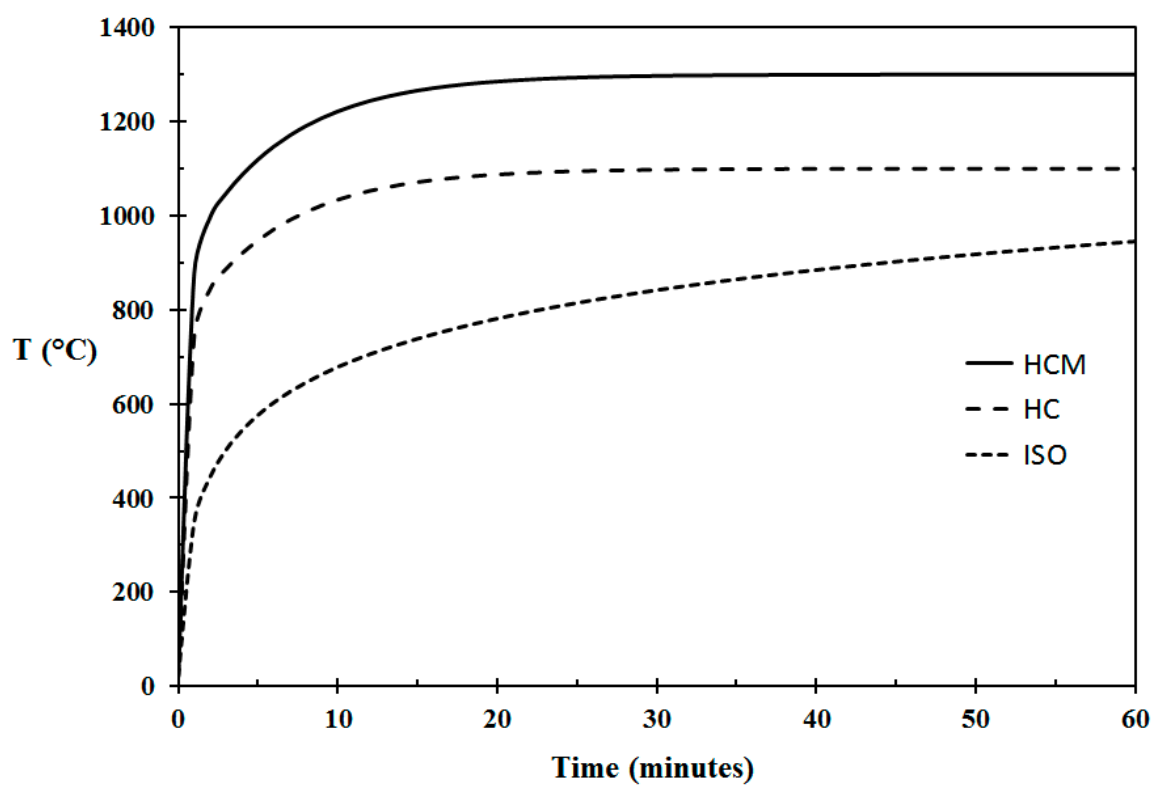

Figure 1. Fire testing temperature time curves.

In industrial fires it is common to distinguish between pool fires resulting from liquid spills and jet fires resulting from the release of pressurized gas. In these two fire regimes, the pool fires are expected to result in heat flux levels of $250 \mathrm{~kW} / \mathrm{m}^{2}$, while jet fires are expected to result in heat flux levels of $350 \mathrm{~kW} / \mathrm{m}^{2}$ [10]. The reason for the jet fires giving more severe heat exposure is due to the higher speed of the combustion products giving a higher convective heat transfer coefficient, as well as the increased turbulence level resulting in cleaner burning and higher flame temperatures. The jet fires are also in general more erosive. Standardized testing is usually performed according to the ISO 22899 Jet Fire Test [11]. The $0.3 \mathrm{~kg} / \mathrm{s}$ propane jet fire, i.e., approximately $14 \mathrm{MW}$ heat release rate, is released 
horizontally through a standardized jet nozzle for various time periods exposing e.g., panels, wall and pipe configurations coated with Passive Fire Protection (PFP) materials.

The radiant heat flux that is absorbed by the exposed object is a function of the temperature and emissivity of the receiving surface, as well as the emissivity of the flames. The net heat flux received by an object fully engulfed in flames is given by:

$$
\dot{Q}_{n e t}^{\prime \prime}=h\left(T_{f}-T_{s}\right)+\varepsilon_{f} \sigma T_{f}^{4}-\varepsilon_{s} \sigma T_{s}^{4}\left(\mathrm{~W} / \mathrm{m}^{2}\right)
$$

where $h(\mathrm{~W} / \mathrm{m} \mathrm{K})$ is the convective heat transfer coefficient, $T_{f}(\mathrm{~K})$ is the flame temperature, $T_{s}(\mathrm{~K})$ is the temperature of the exposed surface, $\varepsilon_{f}$ is the emissivity of the flames, $\varepsilon_{s}$ is the emissivity of the solid and $\sigma$ $\left(5.67 \times 10^{-8} \mathrm{~W} / \mathrm{m}^{2} \mathrm{~K}^{4}\right)$ is the Stefan-Boltzmann constant. The emissivity of the flames is given by:

$$
\varepsilon_{f}=1-\exp (-K L)
$$

where $K(1 / \mathrm{m})$ is the extinction coefficient and $L(\mathrm{~m})$ is the optical flame thickness. Due to the potential size of fires in the oil and gas industry, it is common to assume that the flames are optically thick, i.e., the emissivity is unity.

\subsection{The Test Concept}

Due to the number of parameters exerting influence on the test severity it is not sufficient to e.g., define $1100{ }^{\circ} \mathrm{C}$ recorded by a thermocouple as the target of the flame temperature. Test configuration, heat losses, etc. also needs to be considered. Testing the mockup in a situation that is similar to the real fire is appealing, i.e., where a fire exposes the equipment to be tested. The concept chosen for the present study is shown in Figure 2. It is, however, evident that even though the flames exposing the stainless-steel cladding may be sufficiently hot to comply with e.g., the HC curve, as described in Equation (2), the heat losses from the exposed stainless-steel cladding may reduce the heat exposure substantially. In a small scale, the setup presented in Figure 2 will not work properly due to radiative heat losses.

The convective heat transfer coefficient is dependent on the flame temperature, the hot gas velocity and the turbulence level. It is independent of the flame thickness. However, if the exposed cladding "views" only hot objects, the optical flame thickness becomes much less relevant for heat radiation as long as the exposed surfaces radiate sufficient heat at each other. This may indeed be the case with a fire scenario in a process plant that is dominated by thermally insulated equipment. Reconsidering the set-up to include fire exposed neighbor objects may therefore increase the heat exposure significantly, as shown in Figure 3.

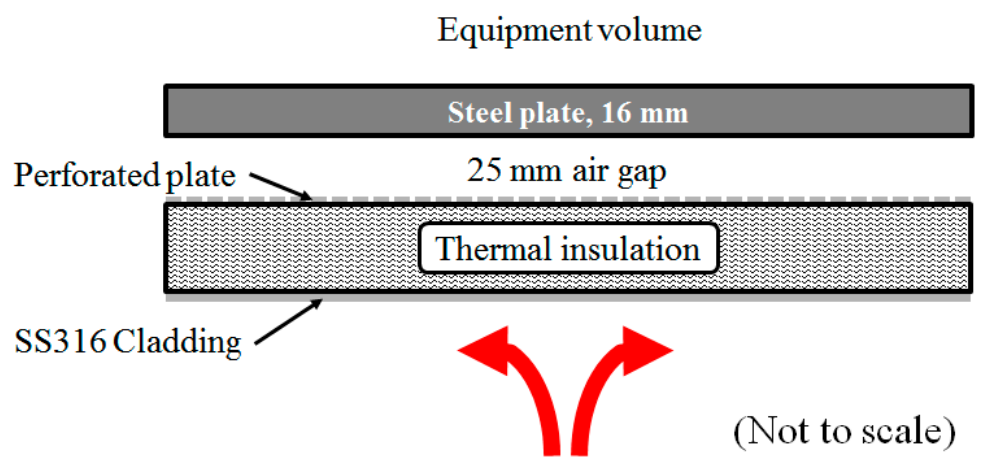

Fire exposure

Figure 2. Conceptual sketch 1 of the fire test set-up. 
In order for the test set-up shown in Figure 3 to work properly, the fire needs to be sufficiently intense and the dimensions must be large enough to ensure a limited size influence. An axisymmetric set-up, with a central cylindrical fire source would represent a simple test configuration. Since it is easy to get hold of radial propane burners, it was convenient to design the mockup in the cylindrical coordinate system. The steel plate was therefore cut to a disk shape. When compared to a real scale industry fire, the fire insulation in Figure 3, i.e., below the flame volume, represents neighbor equipment radiating at the exposed surface of interest.

In the real setting, there is also a back side of the distillation column to which the heat exposed steel will lose heat by convection and radiation. The test setup was therefore designed, as shown in Figure 4. During preliminary testing it was observed that even the set-up as shown in Figures 3 and 4 was "leaking too much heat" to the surroundings. It was therefore tried to "box" the flame zone somewhat in by light weight heat resistant bricks. The purpose of these was to prevent ingress of ambient air entering into and cooling the lower parts of the flame zone and the lower cladding. The light weight bricks blocked the view from the flame zone to ambient conditions and reradiated heat back to the flame zone as soon as their surfaces got heated. This principle is further explained in Section 4 .

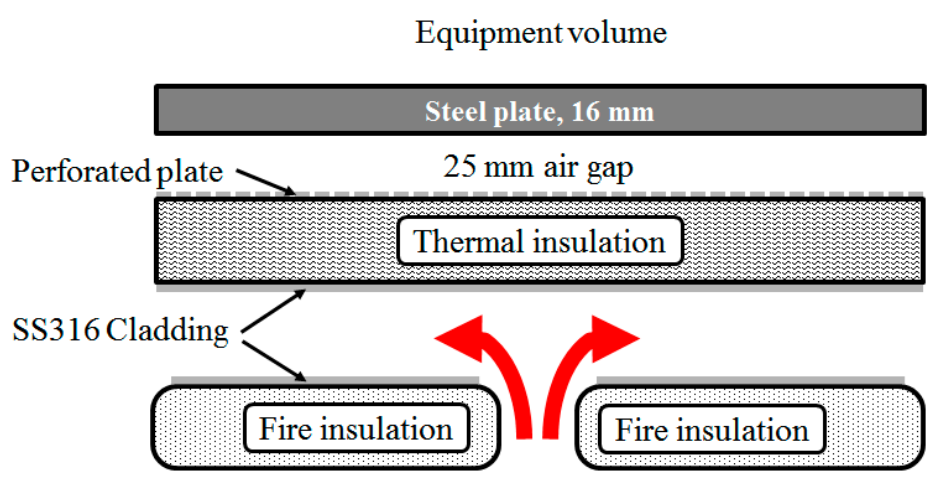

Fire exposure (Not to scale)

Figure 3. Conceptual sketch 2 of the test set-up where the exposed cladding views heat exposed neighbor objects (fire insulated cladding).

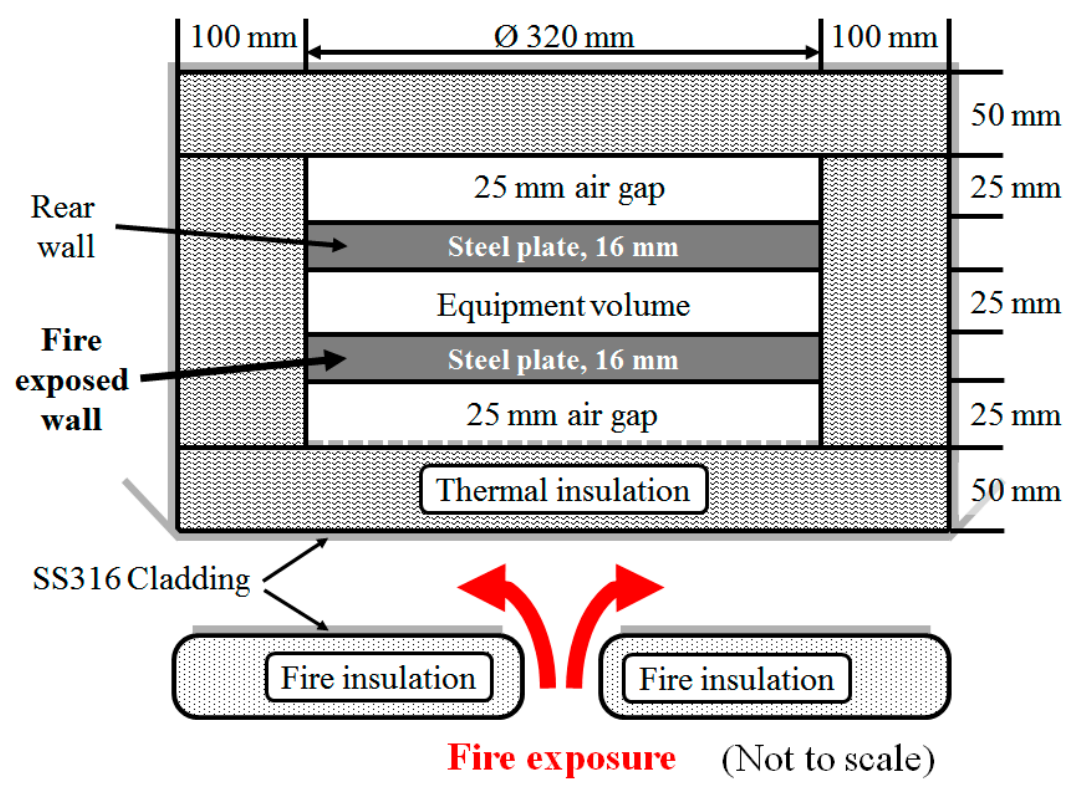

Figure 4. Conceptual sketch of the complete test set-up including mockup. 
Distillation columns are often quite large structures, i.e., diameter $4 \mathrm{~m}$ and height 20-25 m. When considering a wall thickness only a small fraction of the column diameter, i.e., $16 \mathrm{~mm}$ to $4000 \mathrm{~mm}$, the heat flow into the system may be considered one-dimensional. The small scale testing should therefore also be one-dimensional. The radial configuration is very convenient when given a cylindrical burner located at radius zero. Arranging the cylindrical propane fire source vertically, i.e., in positive z-direction, and exposing a horizontal mockup, the heat flow would be one-dimensional through the thermal insulation as long as the size of the mockup is not very large when compared to the deflected flames. The heat exposure should be as independent of radius as possible. Selecting a convenient test specimen diameter is therefore important.

On the other hand, a very low diameter mockup would be more influenced by edge effects due to limited size. It was therefore decided to use steel plate dimension of diameter 20 times the thickness, i.e., diameter $320 \mathrm{~mm}$. This represented a sufficient small scale and a convenient test plate mass $(10 \mathrm{~kg})$ for manual handling. Test specimens larger than that would probably result in less uniform heat flow, or required a larger fire source. Limited radial temperature gradients should nevertheless be confirmed by recording temperatures at different locations during fire testing.

\subsection{Test Temperatures}

The NORSOK S-001 [10] argues that in heat exposure calculations the total heat flux should be set to $250 \mathrm{~kW} / \mathrm{m}^{2}$ for pool fires and $350 \mathrm{~kW} / \mathrm{m}^{2}$ for jet fires. The oil and gas companies have therefore recently started specifying $250 \mathrm{~kW} / \mathrm{m}^{2}$ for pool fires and $350 \mathrm{~kW} / \mathrm{m}^{2}$ for jet fires, e.g., the Statoil requirements for new installations, TR2237 [12]. For heat transfer calculations, this TR recommends a convective heat transfer coefficient $100 \mathrm{~W} / \mathrm{m}^{2} \mathrm{~K}$, flame emissivity unity and the steel and cladding emissivity 0.85 . Flame temperatures of $1050{ }^{\circ} \mathrm{C}$ and $1200{ }^{\circ} \mathrm{C}$ then corresponds to $250 \mathrm{~kW} / \mathrm{m}^{2}$ and $350 \mathrm{~kW} / \mathrm{m}^{2}$ to an object at $20^{\circ} \mathrm{C}$, respectively.

In tests like this, one may introduce cooled total flux meters to record the heat flux levels to the test object. The heat flux meter would, however, in this small-scale setting, not fit in without severely interfering with the heat flux that is received by the test object. Given a combustion chamber propane flame thickness of about $50 \mathrm{~mm}$, the radiation from the exposed solid surfaces quickly dominates the heat flux levels. The best way to ensure proper heat flux levels is then to record the cladding temperatures. This may be done by fixating a thermocouple to the inner cladding surface. Alternatively, introducing a plate thermocouple directly viewing the cladding adds much information about the heat flux levels. A $100 \mathrm{~mm}$ by $100 \mathrm{~mm}$ by $20 \mathrm{~mm}$ thickness type $\mathrm{K}$ plate thermometer (100 mm PT, article number 5928050-001, Pentronic AB, Västervik, Sweden), whose function is explained in [13-16], was therefore introduced flush with the fire insulation below the flame zone viewing directly upwards, as shown in Figure 5. It should be noted that this is the opposite of the orientation intended for such plate thermometers. In this orientation, it is mostly exposed to the heat radiation that it can view from the cladding mockup in addition to convective heat that is received from the propane flame. Facing upwards and aligned flush with the fire insulation cladding it had virtually no influence on heat transfer within the flame zone. The surfaces of the PTs are blasted, and heat treated to obtain an emissivity of about 0.9 , i.e., about the same value as the suggested by the TR2237 [12]. During the fire, it is believed that all of the surfaces approach at least emissivity 0.9 due to oxidation processes. 


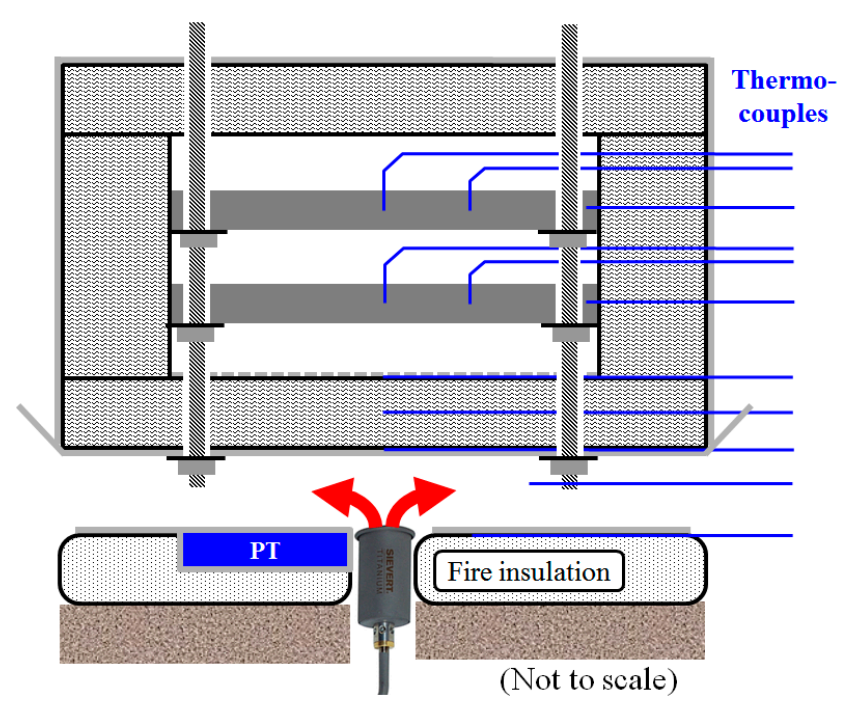

Figure 5. Sketch of mockup including propane gas burner, type K mantle thermocouples, flush mounted plate thermometer (PT), and light weight concrete supporting the fire insulation.

The active part of the plate thermometer, i.e., the stainless-steel plate, had the same thickness as the cladding used in the industry, i.e., $0.7 \mathrm{~mm}$ thickness. The flush mounted plate thermometer allowed for a very compact flame volume, exposing the mockup during testing. It should also be noted that the plate thermometer was not designed for the temperatures it was to be exposed to in the present work. It therefore represented an important, but weak, part of the experimental setup which needed to be validated.

To prevent excessive heat exposure to the mockup, the mockup was covered by cladding on the radial surface as well as on the top surface. The direct fire exposed cladding continued $3 \mathrm{~cm}$ outside the radius of the mockup and was folded and bent $45^{\circ}$ to guide any excess flames away from the mockup, thus reducing the heat stresses and allowing for repeated testing.

\section{Materials and Methods}

The mockup was arranged with type $\mathrm{K}$ thermocouples as indicated in Figure 5. The nearly completed mockup prior to Test 1 is shown in Figure 6. The temperatures were recorded using a datalogger (type 34970A Data Acquisition/Data Logger Switch Unit, Keysight, Santa Rosa, CA, USA (formerly Agilent's Electronic Measurement)).

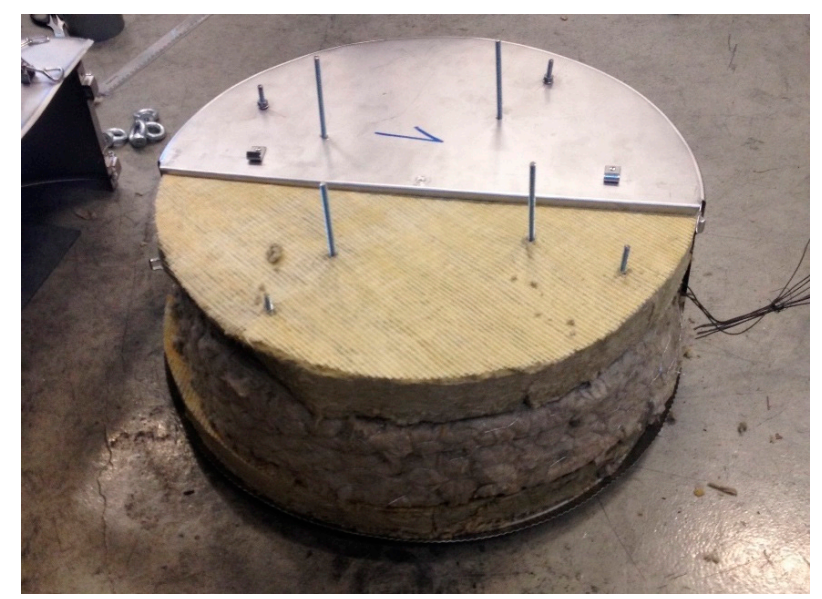

Figure 6. Mockup nearly ready for fire exposure. (Thermocouples exiting to the right). 
A burner (Sievert 346051, Titan $60 \mathrm{~mm}$ diameter), which was fed by propane gas, was used as the fire source, see Figure 7 . The burner was pre-bent about $30^{\circ}$ by the producer and was carefully bent another $60^{\circ}$ (bending radius $50 \mathrm{~mm}$ ) in the present work in order to be arranged horizontally for vertical flames as indicated in Figure 5. It was adjusted to burn with full air access. The gas supply was kept constant during the flame exposure by a flow control unit (Gas control unit, $\mathrm{C}_{3} \mathrm{H}_{8} 225 \mathrm{~L} / \mathrm{min}$, build 2612, Brooks Instrument Inc., Hatfield, PA, USA).

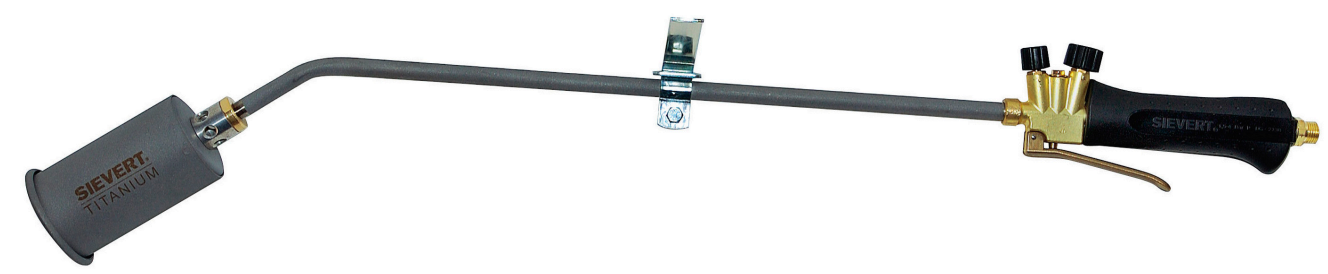

Figure 7. Propane burner (Sievert 346051, titanium $60 \mathrm{~mm}$ diameter).

The mockup ready for testing is shown in Figure 8a,b for Test 1 and Test 2, respectively. In Test 1 , the propane supply was $0.5 \mathrm{~g} / \mathrm{s}$. There were no flame containment bricks along the perimeter during this test. In Test 2, the propane supply was $0.75 \mathrm{~g} / \mathrm{s}$ and light weight bricks (Skamotek 225, Skamol Inc., Nykøping Mors, Denmark) were arranged along the perimeter of the mockup to prevent cold air ingress and limit radiative heat losses from the combustion zone. In addition to contributing in re-radiation, the light weight bricks reduced the view factor of the ambient considerably, as well as ensured gas flow in positive $r$-direction. A photo of the last seconds of Test 2, when some of the light weight bricks were removed for visual inspection, is shown in Figure 9.

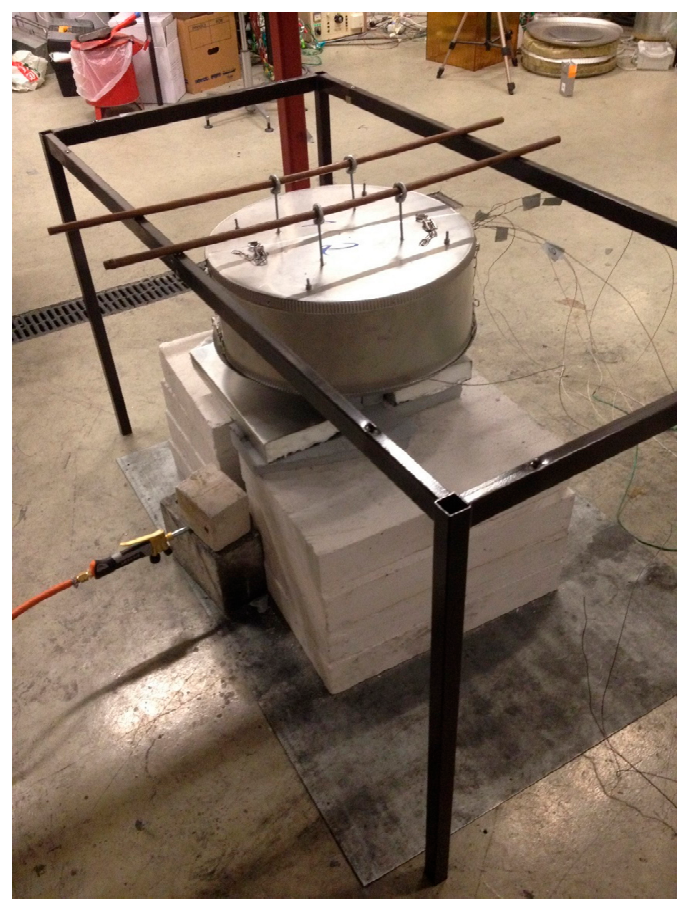

(a)

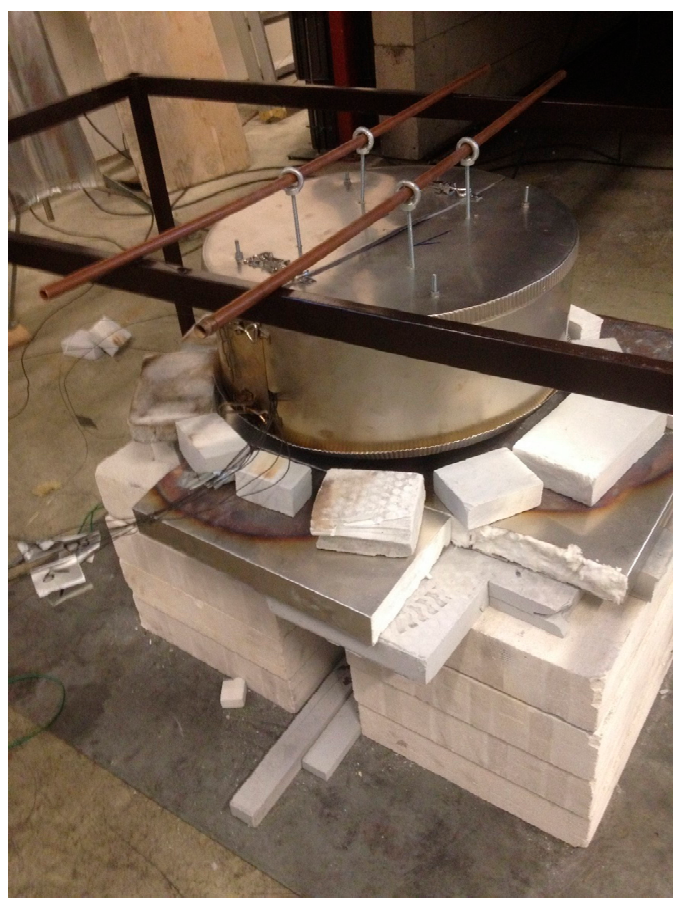

(b)

Figure 8. Ready for fire testing; (a) Test 1 and (b) Test 2. 


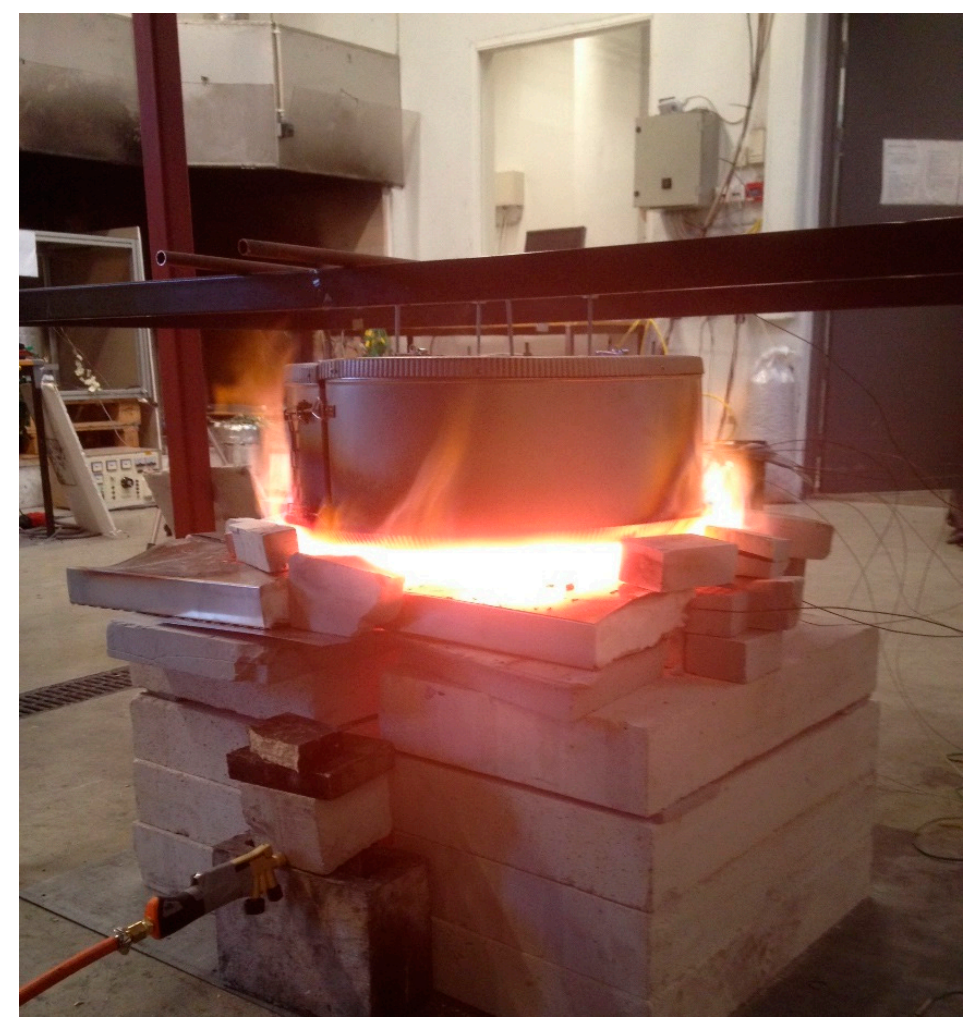

Figure 9. Test 2. (Air flow restrictors removed for visual inspection $30 \mathrm{~s}$ before test completion.)

\section{Results}

The temperatures recorded in Test 1 are shown in Figure 10 (an initial problem with one thermocouple was resolved after about $8 \mathrm{~min}$ ). The recorded flame temperature was above $1100{ }^{\circ} \mathrm{C}$. The plate thermometer (PT) did, however, record much lower temperatures. The explanation for the discrepancy between the two temperature recordings may be a result of the PT also viewing the ambient temperature outside the flame zone and/or cold air entering the lower part of the flame zone cooling the PT. The PT temperature and the temperature inside the mockup cladding show similar temperatures. The temperature recorded just below the cladding protecting the fire insulation below the flame zone show even lower temperatures. This clearly indicates ambient air ingress cooling the lower parts of the flame zone.

The thermal insulation survived the 30+ min heat exposure, as seen in Figure 11a. The cladding suffered some spalling, but it kept its flame deflection capacity during the fire exposure.

The experience with the open flame zone was a strong motivation for (i) increasing the propane flow, and (ii) introducing flame containing light weight bricks limiting ambient air ingress to the flame zone, and serving as ambient conditions radiation shields and re-radiation units.

The temperatures recorded in Test 2 are shown in Figure 12. It is clearly seen that this test exposed the mockup to a far more severe fire scenario. The temperatures recorded in the flame zone were more than $100{ }^{\circ} \mathrm{C}$ higher than in Test 1 . For most of the test the flame temperatures, as well as the PT temperatures, were well above $1200^{\circ} \mathrm{C}$.

The thermal insulation was, as shown in Figure 13a,b, severely deteriorated. Traces of glass-like material were observed within the remains of the thermal insulation. Some of the remains showed a powder like structure, which still reduced the heat flow from the flame exposed cladding to the steel plate. 


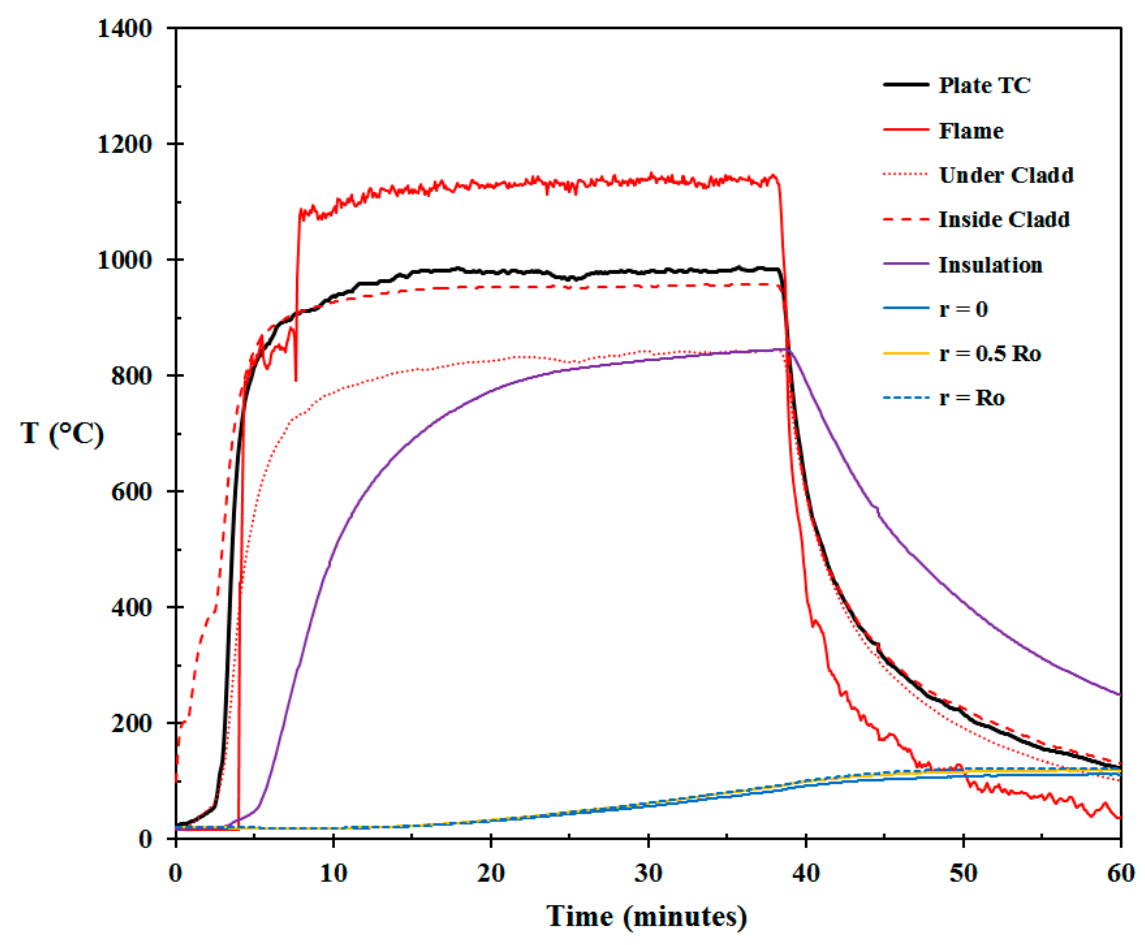

Figure 10. Temperatures recorded in Test 1 (Plate TC is the temperature of the plate thermometer, Flame is the temperature recorded in the flame zone, Under Cladd is the temperature recorded below the lower cladding, Inside Cladd is the temperature recorded inside the upper (exposed) cladding, Insulation is the temperature recorded in the center of the thermal insulation, $r=0, r=0.5$ Ro and $r=$ Ro are the temperatures recorded in the exposed $16 \mathrm{~mm}$ steel plate at $0 \mathrm{~cm}, 8 \mathrm{~cm}$ and $15.5 \mathrm{~cm}$ radius, respectively).

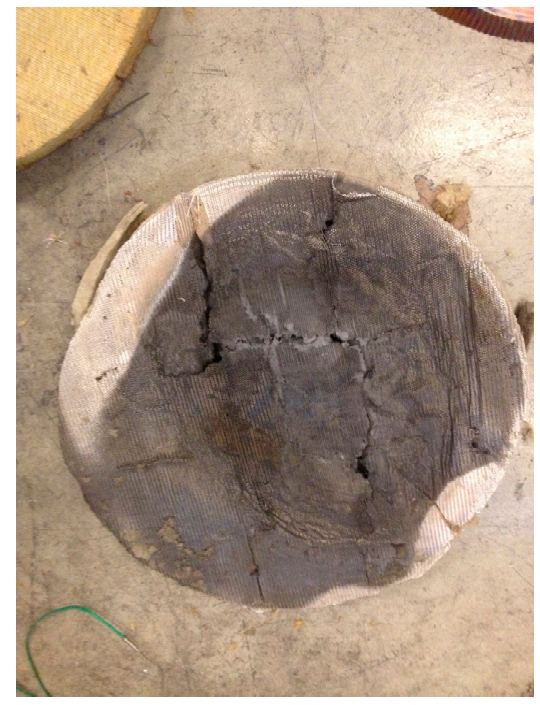

(a)

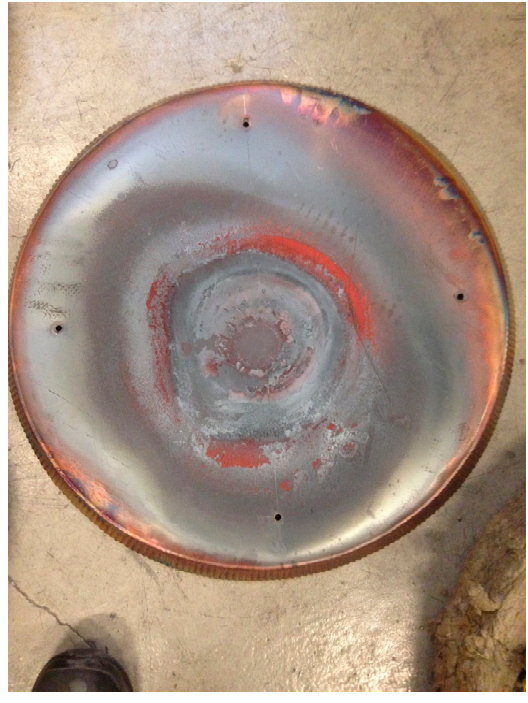

(b)

Figure 11. Thermal insulation (a) and cladding (b) after Test 1. 


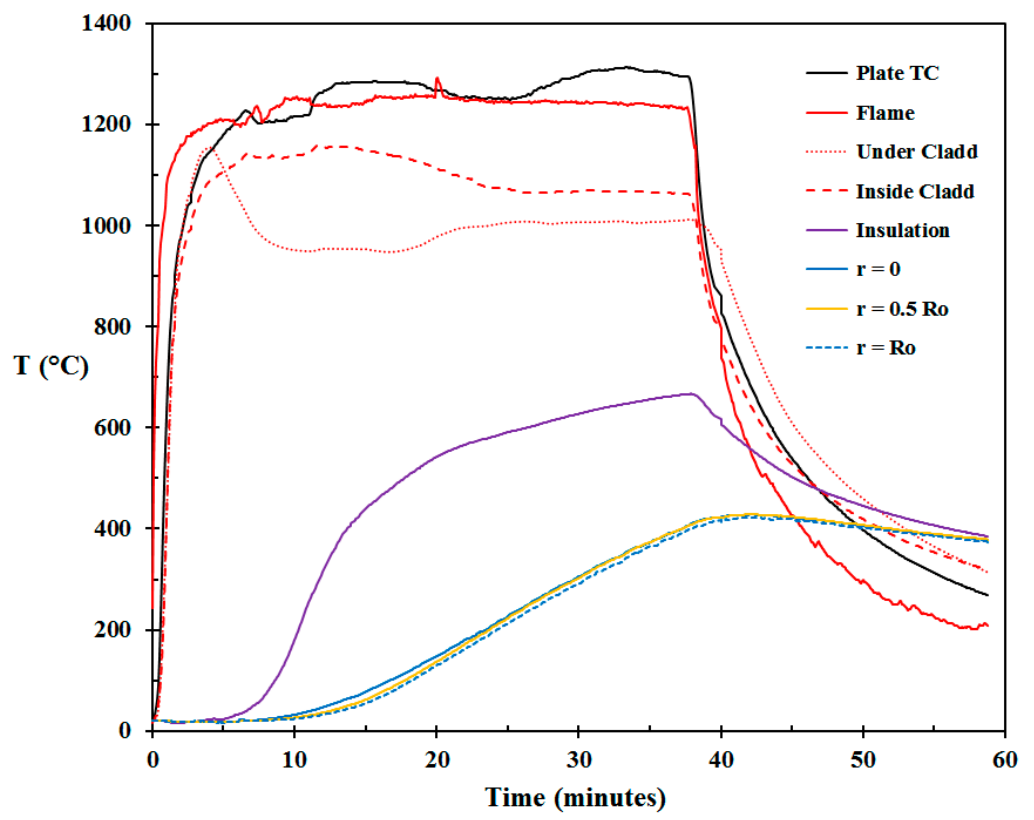

Figure 12. Temperatures recorded in Test 2 (Plate TC is the temperature of the plate thermometer, Flame is the temperature recorded in the flame zone, Under Cladd is the temperature recorded below the lower cladding, Inside Cladd is the temperature recorded inside the upper (exposed) cladding, Insulation is the temperature recorded in the center of the thermal insulation, $r=0, r=0.5$ Ro and $r=$ Ro are the temperatures recorded in the exposed $16 \mathrm{~mm}$ steel plate at $0 \mathrm{~cm}, 8 \mathrm{~cm}$ and $15.5 \mathrm{~cm}$ radius, respectively).

The temperature of the plate thermometer $(\mathrm{PT})$ varied significantly through the test. Spalling, as seen in Figure 14, may influence the temperature to a minor extent. But, as there is only a small heat flow through the thermally insulated PT, there must be other explanations for the varying temperature. Air drafts through the experimental set-up may be a sound explanation.

The temperatures just below the fire insulating cladding during the first 4-5 min closely followed the PT temperatures. This indicates that the ambient air flow keeping the temperature much lower in Test 1 was prevented in Test 2. In Figure 12, it is observed that the temperature below the fire insulation cladding at about $5 \mathrm{~min}$ started to decrease. This is probably due to the thermocouple loosing contact with the cladding due to buckling. The thermocouple inside the mockup cladding was not fixed and lost contact when the cladding surface buckled. A similar effect was not observed for the plate thermometer, in which, the thermocouple junction is welded to the rear side of the exposed surface. The plate thermometer therefore represented the best source of surface temperature recordings in these tests.

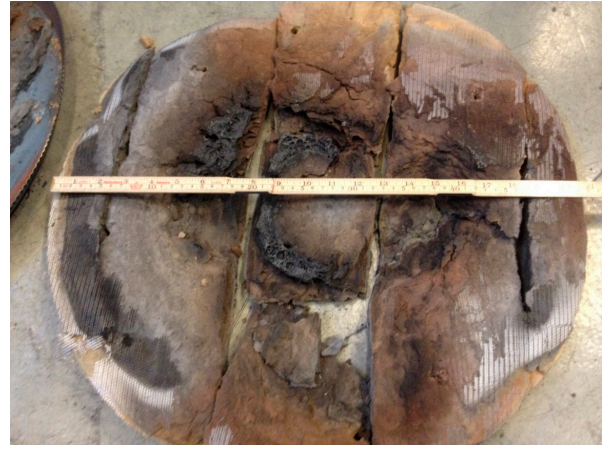

(a)

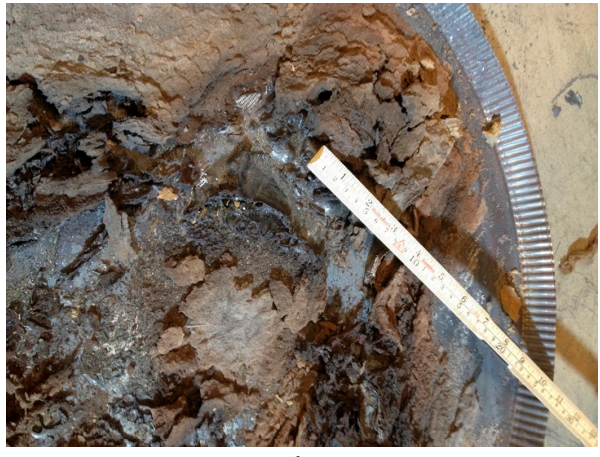

(b)

Figure 13. (a) Upper part of exposed thermal insulation after Test 2 and (b) lower part thermal insulation after Test 2. 


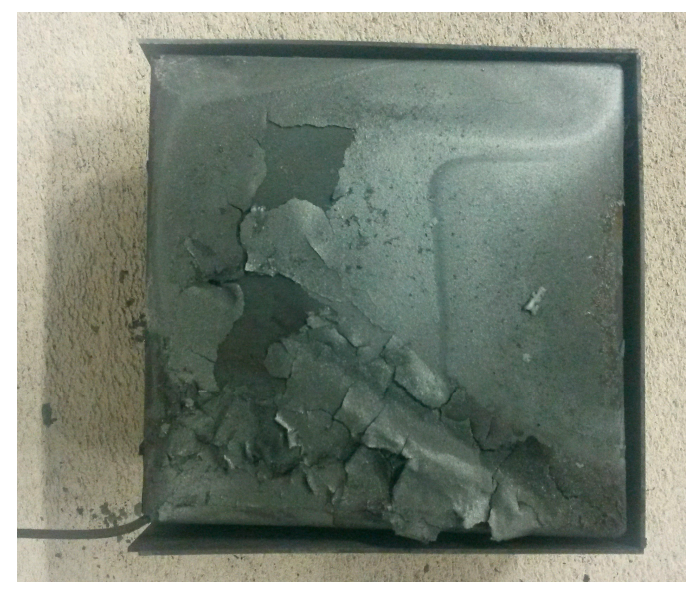

Figure 14. Plate thermometer after Test 2.

The most interesting observation is, however, that the temperatures recorded in the $16 \mathrm{~mm}$ thick steel plate for $30+$ min stayed below $400{ }^{\circ} \mathrm{C}$. This is a good indication of the total system fire resistance in this particular case where the steel plate represented a significant heat sink. It is also seen that the temperatures at the center of the steel plate, i.e., at $r=0$, and halfway out to the perimeter, i.e., at $r=0.5$ Ro, generally do not deviate much. There are, however, some differences between these two temperatures from 10 to $20 \mathrm{~min}$. This may be due to a higher convective heat transfer at the point of propane jet fire impingement, while the gradually increasing radiant heat flux levels average this out. It may, however, also be due to random effects as the thermal insulation starts to disintegrate.

The temperature at the edge of the steel plate, i.e., at $r=$ Ro, seems to lag behind about $12-13^{\circ} \mathrm{C}$. This may be explained by an uneven decomposition of the thermal insulation. It should be noted that the center of the PT, i.e., the thermocouple junction, was located at a radius of about $115 \mathrm{~mm}$. It therefore probably did not record the highest temperatures of the system, which was probably within the inner $20-30 \mathrm{~mm}$ radius of the exposed cladding. The PT temperatures may therefore be representative for a major part of the tested surface.

Conservatively, the highest temperature of the steel plate, i.e., at $r=0$, and the temperature of the plate thermometer could be used to describe the survivability of the modern distance insulation in a fire scenario. Based on the current small scale test, this system in the case with $16 \mathrm{~mm}$ wall thickness would most likely survive more than $30 \mathrm{~min}$ exposure to a hydrocarbon pool fire.

\section{Discussion and Conclusions}

The scope of the present study was to present a new concept for small scale fire testing of hydrocarbon process equipment. By rethinking fire testing from large flames exposure to heat radiation from thermally insulated stainless-steel surfaces, high temperature thermal exposure could be achieved in a small-scale set-up using a $25 \mathrm{~kW}$ test fire. With flame impingement and ambient air flow breakers also working as re-radiation solids, the test setup was capable of producing heat flux levels of $250 \mathrm{~kW} / \mathrm{m}^{2}$, and probably even approaching $350 \mathrm{~kW} / \mathrm{m}^{2}$. It was documented that air flow breakers were necessary to make the small-scale testing work as intended.

The target "fire temperature", given 0.85 in emissivity of the stainless-steel parts, was $1200{ }^{\circ} \mathrm{C}$. The plate thermometer (PT) worked well as an indicator of the fire intensity. Buckling was an issue in the reported tests, both for the mockup cladding and for the fire insulation cladding below the flame zone. The mockup cladding buckled severely, which would also be expected in a real fire. The fire insulation cladding also buckled. It was the first time a PT was tested in an intense fire well above its working temperature by this research group. As mentioned, the plate thermometer did not buckle significantly. It may be that the $100 \mathrm{~mm}$ by $100 \mathrm{~mm}$ size, as well as the welding, bent edges, 
etc. prevented the PT buckling even at temperatures briefly above $1300{ }^{\circ} \mathrm{C}$. Though testing of new equipment was not part of the present study, the authors were quite surprised by the PT performance. It seems promising for future high heat flux level fire testing and research.

It was demonstrated that the thermal insulation was able to keep the temperature of the $16 \mathrm{~mm}$ thick steel plate below $400{ }^{\circ} \mathrm{C}$ for more than 30 min during exposure to heat flux levels that were well above $250 \mathrm{~kW} / \mathrm{m}^{2}$. This result may indicate that work and cost may be saved when refurbishing old hydrocarbon processing equipment. It is believed that the $16 \mathrm{~mm}$ plate acted as a significant heat sink. Without this heat sink in close proximity to the heat exposed thermal insulation, the insulation may disintegrate faster. The current tests can therefore not be used to evaluate situations where thinner metal walls with less heat capacity are to be protected by thermal insulation.

The concept of small scale testing and using the PT as an indirect non-disturbing heat flux level sensor worked well. Fortunately, the exposed stainless-steel surface of the PT had a thickness that was similar to the cladding used in the industry, i.e., used in the mockup. While a radiometer or total heat flux meter would disturb the experimental setup, the PT, when placed flush with the fire insulation cladding and viewing the exposed mockup surface, resulted in a minimum of flame zone disturbances. In such small scale measurements, the PT is therefore a very interesting device for future studies.

In the present work, only two tests were reported. Preliminary tests not reported did, however, also support the findings of the present study. For larger test programs it would also be necessary to do several repetitions at similar conditions to evaluate the variability in testing. That was outside the present concept study.

A further improvement of the method would be to place more than one plate thermometer in the flame zone. This could give valuable information about any irregularities in heat flux levels, etc. Shielding the equipment better from draft current could give less variation in plate thermometer readings.

A result from fire testing and time to reach e.g., $400{ }^{\circ} \mathrm{C}$ is only one of several parameters in risk evaluations regarding fire safety in process plants. Safety for people is the first priority. Time to collapse of pressurized hydrocarbon containing equipment in fires, and potentially a sudden increase in fire severity, must be evaluated against evacuation times. Operation pressure versus design pressure, PSV set-points, i.e., pressure utilization, as well as blow down capacity, also play roles in the final risk evaluation. The fire frequency in the area of interest may also be considered, as well as the problem related to tall and slender structures that represents a threat to neighboring equipment late in a fire scenario. Active fire protection by water cooling may also be considered before a final decision is taken regarding necessary fire resistance of pressurized equipment.

The small scale testing does, however, indicate a potential to reveal important information that may be a part of the complete picture regarding fire risk when modifying existing equipment. When compliance to modern thermal insulation methods would increase the costs and at the same time introduce hot work in a live plant, the presented test methodology may give valuable information in the refurbishment decision processes.

It is recommended to continue the research regarding small scale fire testing of modern thermal insulation methods for thinner, as well as thicker, steel plates. It may also be worthwhile to try to develop small scale fire tests for piping insulation, etc. The small scale method may also have potential as a preliminary test for product development before eventual full scale certified fire testing is undertaken.

Acknowledgments: Statoil Kårstø is acknowledged for funding J.S.B. in this R\&D project. The support of Leif Inge Larsen and Ingvald Olai Heskja for supplying test materials and producing the mockup is very much appreciated.

Author Contributions: T.L. conceived the project idea and did the first calculations and sketches. A.K. arranged the propane burner and flow control unit and made the basic test rig. J.S.B. mounted the mockup for each test and did preliminary testing as well as Test 1 and Test 2 together with A.K. M.M.M. introduced the plate thermocouples and wrote the paper together with J.S.B. and T.L.

Conflicts of Interest: The funding sponsor encouraged the work and several of the sponsor senior personnel were asked for advice during the progress of the work. T.L. has an advisor position at the funding sponsor. None of the participants in the study have any connections to specific equipment being mentioned in the paper. 


\section{References}

1. Kletz, T. What Went Wrong? Case Histories of Process Plant Disasters and How They Could Have Been Avoided, 5th ed.; Institution of Chemical Engineers: London, UK, 2009; ISBN 13:978-1-85617-531-9.

2. U.S. Chemical Safety and Hazard Investigation Board. Investigation Report Executive Summary; Drilling Rig Explosion and Fire at the Macondo Well, Report No. 2010-10-I-OS; U.S. Chemical Safety and Hazard Investigation Board: Washington, DC, USA, 2010.

3. Murray, J.A.; Sander, L.C.; Wise, S.A.; Reddy, C.M. Gulf of Mexico Research Initiative 2014/2015 Hydrocarbon Intercalibration Experiment: Description and Results for SRM 2779, Gulf of Mexico Crude Oil and Candidate SRM 2777 Weathered Gulf of Mexico Crude Oil; NISTIR 8123; National Institute of Standards and Technology: Gaithersburg, MD, USA, 2016.

4. Jet Fire Test Working Group. The Jet-Fire Resistance of Passive Fire Protection Materials; HSE Report OTI 95 634; Health \& Safety Executive-Offshore Technology Report; Jet Fire Test Working Group: Sheffield, UK, 1995; ISBN 0-7176-1166-3.

5. Roberts, T.A.; Shirvill, L.C.; Waterton, K.; Buckland, I. Fire resistance of passive fire protection coatings after long term weathering. Process Saf. Environ. Prot. 2010, 88, 1-19. [CrossRef]

6. Collier, K. Insulation. Chem. Eng. Prog. 2002, 98, 47.

7. International Organization Standardization (ISO). Fire-Resistance Tests_Elements of Building Construction; International Organization Standardization: Geneve, Switzerland, 2007.

8. Norsk Standard. Fire Resistance Tests-Part 1: General Requirements; NS-EN 1363-1:2012, standard.no; Norsk Standard: Lysaker, Norway, 2012.

9. Taillefer, N.; Carlotti, P.; Larive, C.; Lemerle, C.; Avenel, R.; Pimienta, P. Ten Years of Increased Hydrocarbon Temperature Curves in French Tunnels. Fire Technol. 2013, 49, 531-549. [CrossRef]

10. Norsk Standard. Technical Safety, NORSOK Standard, 4th ed.; S-001, standard.no; Norsk Standard: Lysaker, Norway, 2008; p. 62.

11. International Organization for Standardization. Determination of the Resistance to Jet Fires of Passive Fire Protection Materials_-Part 1: General Requirements; International Organization for Standardization: Geneva, Switzerland, 2007; p. 40.

12. Statoil, TR2237. Performance Standards for safety systems and barriers-Onshore. Statoil Tysværvåg Norway 2015, 3, 105.

13. Wickström, U. The plate thermometer-A simple instrument for reaching harmonized fire resistance tests. Fire Technol. 1994, 30, 195-208. [CrossRef]

14. Ingason, H.; Wickström, U. Measuring incident radiant heat flux using the plate thermometer. Fire Saf. J. 2007, 42, 161-166. [CrossRef]

15. Häggkvist, A.; Sjöström, J.; Wickström, U. Using plate thermometer measurements to calculate incident heat radiation. J. Fire Sci. 2013, 31, 166-177. [CrossRef]

16. Sjöström, J.; Amon, F.; Appel, G.; Persson, H. Thermal exposure from large scale ethanol fuel pool fires. Fire Saf. J. 2015, 78, 229-237. [CrossRef]

(C) 2017 by the authors. Licensee MDPI, Basel, Switzerland. This article is an open access article distributed under the terms and conditions of the Creative Commons Attribution (CC BY) license (http:/ / creativecommons.org/licenses/by/4.0/). 